\title{
REVISANDO E APROXIMANDO ORIENTAÇÃO EMPREENDEDORA E MOBILIDADE EMPRESARIAL
}

\section{REVIEWING AND LINKING ENTREPRENEURIAL ORIENTATION AND ORGANIZATIONAL MOBILITY}

Cristina Dai Prá Martens PMPGP/UNINOVE - SP cristinadpmartens@gmail.com

Ana Claudia Belfort UNINOVE - SP belfortanaclaudia@gmail.com

Henrique Mello Rodrigues de Freitas PPGA/UNINOVE - SP Freitas138@gmail.com

Submissão: 05/08/2014 Aprovação: 02/12/2016 


\section{RESUMO}

Diversos autores vêm salientando a preocupação das organizações com a adoção de estratégias corporativas orientadas ao empreendedorismo, projetando luzes para como aspectos do ambiente podem influencia-la. Uma de suas possíveis extensões, a associada às tecnologias de informação móveis (TIMs), contudo, parece ainda hoje inexplorada pela literatura. Este artigo, de natureza teórico-conceitual, insere-se justamente neste contexto. Adotando como base as cinco dimensões da orientação empreendedora (OE) - inovatividade, proatividade, assunção a riscos, autonomia e agressividade competitiva -, este artigo busca identificar as relações conceituais entre OE e a mobilidade empresarial, decorrente do uso de TIMs. Desenvolveu-se um estudo exploratório de abordagem teórico-conceitual, baseado em pesquisa bibliográfica. Como resultado obteve-se um quadro que apresenta reflexões acerca de possíveis efeitos da mobilidade sobre as dimensões da OE. Adicionalmente, são sintetizados os elementos da $\mathrm{OE}$ que podem ser utilizados como base para a realização de estudos empíricos, bem como são feitas proposições de pesquisas.

Palavras-chave: Tecnologias de Informação Móveis. Tecnologias Móveis. Orientação Empreendedora. Empreendedorismo. Mobilidade Empresarial. 


\begin{abstract}
Several authors have pointed out a concern of organizations with an adoption of corporate strategies oriented to entrepreneurship, projecting lights to the concept of environment to influence it. One of its extensions, one associated with mobile information technologies (TIMs), however, still seems to be unexplored in the literature. This article, of a theoreticalconceptual nature, is inserted in this context. Based on five dimensions of the entrepreneurial effort (OE) - innovation, proactivity, risk assumption, autonomy and competitive aggressiveness - this article seeks to identify as concepts of relations between OE and business mobility, an exploratory approach Theoretical-conceptual, based on bibliographical research. As result, a table was presented that presents reflections on mobility on the dimensions of OE. In addition, OE elements are synthesized that can be used as a basis for an empirical study.
\end{abstract}

Keywords: Mobile Information Technology. Mobile Technologies. Entrepreneurial Orientation. Entrepreneurship. Organizational Mobility. 


\section{INTRODUÇÃO}

Dentre as linhas temáticas dos estudos acerca do empreendedorismo, encontra-se a pesquisa desse tema no nível organizacional, denominado como postura empreendedora de uma organização por Covin e Slevin (1989) e como Orientação Empreendedora (OE) por Lumpkin e Dess (1996). A OE nas organizações constitui uma das poucas áreas de pesquisa em empreendedorismo com um cumulativo corpo de conhecimento em desenvolvimento (RAUCH; WIKLUND; LUMPKIN; FRESE, 2009; COVIN; LUMPKIN, 2011). Fernandes e Santos (2008), Silva, Gomes e Correia (2009) e Martens, Freitas e Andres (2011) são alguns dos pesquisadores que possuem estudos com essa temática no Brasil.

Considerando que o ambiente que cerca as organizações constitui-se de um mercado turbulento, sujeito a mudanças frequentes, Engelen, Kube, Schmidt e Flatten (Article in press) afirmam que a OE permite a tais organizações uma atuação mais proativa frente ao mercado, uma vez que a capacidade dinâmica de adquirir, assimilar, transferir e explorar novos conhecimentos decorrentes de variáveis externas permite à organização implementar uma abordagem estratégica orientada ao empreendedorismo.

Face às constantes mudanças no mundo corporativo, outro tema tem permeado as pesquisas no meio acadêmico: os avanços da tecnologia da informação. Tais avanços têm impulsionado as organizações a inovarem tecnologicamente, a fim de se manterem ativas no mercado (BELFORT; MARTENS, 2014; SACCOL, REINHARD, 2007). A mobilidade tecnológica surge como um importante recurso na gestão das organizações e pode ter algum reflexo no empreendedorismo organizacional.

Segundo Saccol e Reinhard (2007), os dispositivos móveis (laptops, smartphones e tablets, dentre outros) constituem as Tecnologias de Informação Móveis (TIMs), ou simplesmente 'tecnologias móveis', cujas características incluem a portabilidade e a capacidade de se levar a qualquer lugar, podendo ser operados conectados ou não a uma rede. Atualmente, várias organizações utilizam dispositivos móveis de modo a interagir com seus stakeholders, uma vez que podem conter aplicativos e ferramentas diversas, além de acesso à internet, caracterizando a existência da mobilidade (KLEINROCK, 1996; KAKIHARA; SØRENSEN, 2001; KALAKOTA; ROBINSON, 2002). Aliado a esse fato, verifica-se que novas organizações estão especializando-se em desenvolvimento de funções e aplicativos voltados às tecnologias móveis (CHUNG; LEE; CHOI, 2014), que permitem aos colaboradores acesso em tempo real às informações organizacionais, maior colaboração entre 
si, com outras unidades das empresas e até mesmo com outras organizações e parceiros de negócios (UNHELKAR; MURUGESAN, 2010 apud CHUNG; LEE; CHOI, 2014).

Com base no contexto inicialmente delineado, centrado na relevância dos temas empreendedorismo e mobilidade no ambiente organizacional, aliado à sinalizações previas da literatura que sugerem que o uso de tecnologias móveis tende a favorecer a manifestação das dimensões da orientação empreendedora, em especial no que se refere à autonomia dos indivíduos (SACCOL; REINHARD, 2007; BESSEYRE DES HORTS, 2008), à inovação em processos e em modelos de negócios e de gestão (ANDRIESSEN; VARTIAINEN, 2010) e também ações proativas. Mendieta et al. (2013) analisaram o uso de TIMs e a OE em uma organização, apontando para efeitos positivos dessa relação no contexto estudado. Embora essas inciativas, há lacuna de estudos que abordem a relação entre o uso de TIMs e o empreendedorismo organizacional. Considerando os impactos que as tecnologias móveis podem causar nas organizações e a sinalização da literatura de que as diferenças de empreendedorismo nas organizações podem ser atribuídas a combinações de fatores individuais, organizacionais e ambientais (MILLER, 1983; LUMPKIN; DESS, 1996), pressupõe-se que a mudança propiciada pelo uso de tecnologias móveis pode também afetar a OE da organização.

Assim, este artigo tem como norteadora a seguinte questão de pesquisa: Como as tecnologias móveis afetam a orientação empreendedora de uma organização? Apresenta-se como objetivo identificar as relações conceituais entre a $\mathrm{OE}$, considerando suas dimensões inovatividade, assunção de riscos, proatividade, autonomia e agressividade competitiva, e a mobilidade empresarial, decorrente do uso de TIMs.

Para isso, utilizou-se a pesquisa exploratória com vistas à obtenção de maior familiaridade com o tema (LAKATOS; MARCONI, 2010; MARTINS; THEÓPHILO, 2009; GIL, 2010). A pesquisa bibliográfica foi escolhida como estratégia de pesquisa, envolveu a realização de uma revisão de artigos que abordam os eixos teóricos OE e mobilidade, com vistas à obtenção de um quadro teórico-conceitual sintético sobre o assunto, identificando pontos de aderência entre os temas. Mediante busca na base Web of Science, foram identificados artigos seminais e atuais sobre cada um dos temas. A busca foi realizada em duas etapas, sendo a primeira focada nos termos "entrepreneurial orientation" e "orientação empreendedora"; e a segunda, nos termos "mobility", "mobile technology", "mobilidade" e “tecnologia móvel”. Uma vez identificados, os artigos foram baixados. Na sequência, 
procedeu-se à leitura dos artigos e ao desenvolvimento do texto corrente. A escolha de qual artigo incluir no texto decorreu de sua aderência à temática proposta na pesquisa.

Após esta introdução, a seção 2 tem como foco a revisão da literatura a respeito da $\mathrm{OE}$ e mobilidade tecnológica. Em seguida, na seção 3, é apresentado um quadro associativo que demonstra a relação existente entre os dois eixos de estudo, com reflexões sobre os possíveis efeitos da mobilidade no empreendedorismo organizacional. Por fim, na seção 4, são feitas as considerações finais, apresentadas as limitações deste estudo e as propostas para novas pesquisas.

\section{REFERENCIAL TEÓRICO}

Nesta seção, a literatura é revisitada e aspectos conceituais em relação à $\mathrm{OE}$ e ao uso de tecnologias de informações móveis são retomados, com vistas a destacar os principais elementos de tais eixos teóricos.

\subsection{Orientação Empreendedora em organizações}

O tema empreendedorismo tem evoluído a passos largos, sobretudo em se tratando do contexto organizacional, permeando diversas pesquisas e estudos a seu respeito (SHORT et al., 2001). Nesse contexto destaca-se a temática OE, que se refere ao empreendedorismo no nível organizacional, ou seja, ao estudo dos métodos, práticas e estilos de tomada de decisão gerencial utilizados pelas organizações para atuarem de modo empreendedor (LUMPKIN; DESS, 1996). Segundo Covin e Slevin (1989), trata-se da postura empreendedora de uma organização.

Shane e Venkataraman (2000) afirmam que o empreendedorismo é influenciado não somente por características pessoais, mas também por situações e ambientes aos quais as organizações pertencem, vez que o comportamento empreendedor surge como uma resposta às ameaças e oportunidades do ambiente. Tal posição é corroborada por Lumpkin e Dess (1996), ao citarem que a existência de empreendedorismo nas organizações decorre de sua OE, que por sua vez é influenciada por fatores individuais, organizacionais e ambientais.

Para Covin e Slevin (1989), a OE de uma organização é demonstrada à proporção em que os gestores estão dispostos a assumir riscos, a favorecer mudanças e inovação e a competir agressivamente com outras organizações. Já para Lumpkin e Dess (1996), esse 
constructo é caracterizado por meio da existência de cinco dimensões: autonomia, capacidade de inovação, assunção de riscos, proatividade e agressividade competitiva; a presença de tais dimensões em maior ou menor intensidade retrata o quanto a organização é orientada ao empreendedorismo.

No presente estudo, é adotado o conceito de OE proposto por Lumpkin e Dess (1996), baseado em cinco dimensões. Nesse sentido, torna-se necessário conceituar cada uma das dimensões da $\mathrm{OE}$ apregoadas pelos autores, visando obter um melhor entendimento de como tais dimensões caracterizam-se no contexto organizacional (Quadro 1).

Quadro 1. Dimensões da orientação empreendedora, comportamento e características

\begin{tabular}{|c|c|c|}
\hline Dimensão & $\begin{array}{l}\text { Comportamento da } \\
\text { Organização }\end{array}$ & Diz respeito a(o) \\
\hline Autonomia & $\begin{array}{l}\text { A organização preza a } \\
\text { ação independente de } \\
\text { equipes autônomas e de } \\
\text { colaboradores. }\end{array}$ & $\begin{array}{l}\text { (a) equipe (líderes e times de trabalho); } \\
\text { (b) centralização de liderança e delegação de } \\
\text { autoridade; } \\
\text { (c) pensamentos e iniciativas } \\
\text { empreendedores; e, } \\
\text { (d) pensamentos e ações independentes. }\end{array}$ \\
\hline Inovatividade & $\begin{array}{l}\text { A organização se engaja } \\
\text { e apoia novas ideias, } \\
\text { novidades, experimentos } \\
\text { e processos criativos que } \\
\text { possam resultar em } \\
\text { novos produtos, serviços } \\
\text { ou processos. }\end{array}$ & $\begin{array}{l}\text { (a) produtos e serviços novos; } \\
\text { (b) processos inovadores; } \\
\text { (c) investimento de recursos financeiros em } \\
\text { inovação; } \\
\text { (d) pessoas envolvidas e comprometidas em } \\
\text { atividade de inovação; } \\
\text { (e) processos criativos e inovadores; e, } \\
\text { (f) iniciativas inovadoras e diferenciadas, de } \\
\text { difícil imitação. }\end{array}$ \\
\hline $\begin{array}{l}\text { Assunção de } \\
\text { riscos }\end{array}$ & $\begin{array}{l}\text { A organização possui } \\
\text { propensão a assumir } \\
\text { riscos e a se engajar em } \\
\text { projetos de alto risco. }\end{array}$ & $\begin{array}{l}\text { (a) assunção de riscos gerais (tendência a } \\
\text { assumir riscos); } \\
\text { (b) risco na decisão (visão pouco } \\
\text { conservadora em relação a riscos); } \\
\text { (c) riscos financeiros e em negócios } \\
\text { (tendência a assumir riscos para atingir os } \\
\text { objetivos da organização). }\end{array}$ \\
\hline Proatividade & $\begin{array}{l}\text { A organização antecipa- } \\
\text { se ao mercado e } \\
\text { aproveita oportunidades, } \\
\text { influenciando o ambiente } \\
\text { ou iniciando mudanças. }\end{array}$ & $\begin{array}{l}\text { (a) monitoramento contínuo do ambiente; (b) } \\
\text { atitude de antecipação à concorrência; (c) } \\
\text { participação e resolução de problemas, de } \\
\text { modo descentralizado; e, } \\
\text { (d) flexibilidade tecnológica. }\end{array}$ \\
\hline $\begin{array}{l}\text { Agressividade } \\
\text { Competitiva }\end{array}$ & $\begin{array}{l}\text { A organização reage à } \\
\text { concorrência e às } \\
\text { ameaças do mercado, } \\
\text { com respostas rápidas a } \\
\text { ações do mercado } \\
\text { concorrente. }\end{array}$ & $\begin{array}{l}\text { (a) postura agressiva perante concorrentes, } \\
\text { reagindo às ações deflagradas por estes no } \\
\text { mercado; } \\
\text { (b) competição financeira, tais como de } \\
\text { preços menores do que os da concorrência; (c) } \\
\text { postura competitiva, centrada no combate às }\end{array}$ \\
\hline
\end{tabular}


tendências que possam ameaçar sua sobrevivência; e,

(d) ações de marketing mais agressivas.

Fonte: elaborado com base em MARTENS, C. D. P.; FREITAS, H. M. R.; ANDRES, R. Desenvolvimento da Orientação Empreendedora em Empresas de Software: Proposições Preliminares. REAd, v. 69, n. 2, p. 424-450, maio/agosto 2011.

Tomando-se por base o Quadro 1, é possível verificar que as dimensões da $\mathrm{OE}$ constituem-se de elementos cuja existência permite observar e analisar a $\mathrm{OE}$ nas organizações. Nesse contexto, convém salientar que alguns estudos alertam para o fato de que quanto maior o nível de OE das organizações, melhor será o seu desempenho (MILLER, 1983; COVIN; SLEVIN, 1991; ZAHRA, 1993; ZAHRA; COVIN, 1995; WIKLUND, 1999; WIKLUND; SHEPHERD, 2005; RAUCH; WIKLUND; LUMPKIN; FRESE, 2009). Essa afirmação é corroborada por meio de estudos empíricos realizados em organizações brasileiras (MELLO; PAIVA JÚNIOR; SOUZA NETO; LUBI, 2006; CASTANHAR; DIAS; ESPERANÇA, 2006; FERNANDES; SANTOS, 2008).

No entanto, Lumpkin e Dess (1996) argumentam que a existência de todas as dimensões no contexto organizacional nem sempre está atrelada a negócios bem sucedidos. O sucesso pode ocorrer mesmo em organizações que apresentem apenas algumas das cinco dimensões, uma vez que a sua existência dependerá do contexto no qual a organização está inserida. Segundo esses mesmos autores, as diferenças da OE nas organizações podem ser atribuídas a várias combinações de fatores individuais, organizacionais e ambientais, que influenciam o como e o porquê do empreendedorismo em cada organização.

Shane e Venkataraman (2000) corroboram com Lumpkin e Dess (1996) e afirmam que o empreendedorismo não pode ser explicado considerando apenas características pessoais. A influência das situações e do ambiente é relevante, uma vez que o engajamento em comportamentos empreendedores geralmente responde a situações e oportunidades do ambiente. Miller (1983), por sua vez, afirma que variáveis ambientais, estruturais, estratégicas e a própria personalidade do líder podem influenciar a forma como o empreendedorismo se desenvolve no contexto organizacional.

Segundo Covin, Green e Slevin (2006), a capacidade da OE de cumprir sua promessa como um importante driver de desempenho da organização depende da forma como ela ocorre. Wales, Monsen e McKelvie (2011), diferentemente da maioria dos estudiosos da temática, afirmam que a $\mathrm{OE}$ é heterogênea, podendo manifestar-se de diferentes maneiras, podendo ser vislumbrada considerando três dimensões: (a) verticalmente, em termos de níveis hierárquicos e grupos de organizações; (b) horizontalmente, em termos de divisões e 
unidades de negócios; e, (c) temporalmente, em termos de tempo e estágios de desenvolvimento.

Por fim, o quanto uma organização é inovadora, é predisposta a correr riscos, antecipase ao mercado e aproveita oportunidades de forma proativa, atua com equipes autônomas e responde rapidamente à concorrência e ameaças do mercado, depende de inúmeros fatores, dentre os quais o desenvolvimento tecnológico. A tecnologia tende a impulsionar mudanças nos produtos, nos serviços e nos processos de trabalho, bem como a alterar o modo da organização relacionar-se com o ambiente, seja no trabalho de equipes, na gestão, na relação com os stakeholders, entre outros, tornando eminente o impacto no empreendedorismo a nível organizacional.

Uma das mudanças que maior impacto tem causado nas organizações nos últimos anos é o avanço das tecnologias de informação, em especial a partir do advento da internet e, mais recentemente, com o crescimento do uso de dispositivos móveis. Nesse contexto, torna-se pertinente abordar a mobilidade empresarial, propiciada pelo uso de tecnologias móveis no contexto organizacional, que tem afetado o modo de trabalhar e de gerir as organizações, e que pode ter efeitos no empreendedorismo organizacional.

\subsection{Mobilidade decorrente do uso de Tecnologias de Informação Móveis (TIMs)}

As tecnologias de informação móveis, sem fio e ubíquas estão entre os temas mais discutidos na área de Sistemas de Informação atualmente (SACCOL; REINHARD, 2007). Essas tecnologias têm ocupado um lugar considerável no desenvolvimento das organizações, seja por meio de telefones, computadores portáteis, redes sem fio, ou outros, permitindo aos colaboradores que desenvolvam suas atividades sem a necessidade de estar em um local específico ou em um horário definido. A adoção de TIMs permite eliminar as barreiras de tempo e lugar (BESSEYRE DES HORTS, 2008).

Ao optar pela adoção de TIMs, a organização está tomando uma decisão importante, muitas vezes de cunho estratégico, sobretudo em se considerando que a adoção de tais tecnologias tende a alavancar os benefícios da mobilidade para os negócios (SCORNAVACCA; BARNES, 2008; BASOLE, 2008).

Não somente as TIMs, como também as tecnologias sem fio (wireless), ubíquas (ubiquitous), nômades (nomadic), de comércio móvel (m-commerce) e de negócios móveis (m-business) permeiam constantemente debates relacionados a tecnologias de informação, 
pois permitem às pessoas desenvolverem suas atividades em qualquer local ou horário específicos (SACCOL; REINHARD, 2007).

Segundo o IDC, durante o ano de 2014 o investimento em TI chegará a 139.000.000 mil dólares, crescendo 8,4\% em relação a 2013, assim como a participação no mercado dos dispositivos móveis inteligentes, tais como smartphones e tablets, sofrerá um acréscimo de $34 \%$ e $18 \%$, respectivamente, alterando cada vez mais o contexto organizacional (IDC LATIN AMERICA PREDICTIONS, 2014). Tal estudo salienta também que o mercado tradicional de computadores na América Latina tem apresentado situação similar ao mercado global, com redução de $7 \%$ nas vendas no ano de 2013, no qual foram vendidas 34 milhões de unidades de desktops; em contrapartida, no que diz respeito ao mercado dos dispositivos móveis (smartphones e tablets), o crescimento girou em torno de $80 \%$ no ano de 2013 , chegando a monta de 111 milhões de dispositivos vendidos. Para 2014, estão previstos uma redução de aproximadamente $8 \%$ na venda de computadores/desktops e um aumento de cerca de $28 \%$ na venda de smartphones e tablets.

Em relação ao mercado brasileiro, estudos realizados pelo IDC BRASIL (2014b), apontam um crescimento de $157 \%$ (8,4 milhões de unidades) nas vendas de tablets, se comparado ao volume comercializado em 2012. Ainda em 2013 a venda de smartphones cresceu $123 \%$ em relação a 2012, atingindo o recorde de 35,6 milhões de unidades vendidas, ou seja, 68 smartphones por minuto (IDC BRASIL, 2014c). Para o IDC Brasil (2014a), a venda de smartphones e tablets deverá ultrapassar 58 milhões de unidades e mais de 5 milhões de dispositivos pessoais serão utilizados dentro das empresas, repercutindo no surgimento de novas bases de gestão, ferramentas e aplicativos destinados aos dispositivos móveis.

Nesse contexto evidencia-se que, em razão do aumento no uso de dispositivos móveis como ferramentas organizacionais, a mobilidade tende a gerar efeitos significativos nas organizações. As tecnologias móveis sem fio abrem uma nova perspectiva para produtos, serviços, trabalho e organização, uma vez que permitem maior mobilidade do que as tecnologias com fio, além de maiores possibilidades de selecionar mais livremente o local de trabalho (ANDRIESSEN; VARTIAINEN, 2006).

Inquietações relacionadas à criação, escolha, adaptação e efeitos do uso de tecnologias móveis emergiu em meio a esse cenário, diante do fato de que diversas organizações adotaram tais tecnologias a fim de interagir com seus stakeholders. Nesse contexto, emergem novos 
temas associados ao uso de tecnologias móveis no ambiente organizacional: empresa móvel e virtualização (Quadro 2).

Quadro 2. Novos temas associados à mobilidade tecnológica

\begin{tabular}{|l|l|}
\hline Tema & Conceito \\
\hline $\begin{array}{l}\text { Empresa } \\
\text { móvel }\end{array}$ & $\begin{array}{l}\text { Nova forma de organização, cujas características principais são a agilidade } \\
\text { e a adaptabilidade às pressões do ambiente. Tal conceito emerge da } \\
\text { transformação causada pelas tecnologias móveis (BESSEYRE DES } \\
\text { HORTS, 2008), cujo uso permite a realização das tarefas com maior } \\
\text { rapidez e eficiência, inclusive à distância, além de propiciar apoio à tomada } \\
\text { de decisão, vez que os gestores possuem informações atualizadas e } \\
\text { precisas, em tempo integral e em qualquer hora ou lugar. }\end{array}$ \\
\hline Virtualização & $\begin{array}{l}\text { Utilização de um espaço virtual para facilitar interações relacionadas às } \\
\text { atividades organizacionais e ao acesso a recursos e capacidades que podem } \\
\text { não estar disponíveis em um mesmo espaço físico, podendo estar } \\
\text { geograficamente dispersos (SHEKHAR, 2006). }\end{array}$ \\
\hline
\end{tabular}

Fonte: elaborado pelos autores.

O avanço da mobilidade tecnológica pelo uso de dispositivos móveis no contexto organizacional causou uma revolução na forma de atuar das organizações transformando as relações de trabalho (BESSEYRE DES HORTS; ISAAC; LECLERCQ, 2006). Isso pode trazer contribuições e limitações tanto para a organização como para o colaborador.

Para Machado e Freitas (2009), o uso de tecnologias móveis no contexto organizacional pode contribuir para facilitar a interação com e entre seus stakeholders, propiciar maior agilidade em determinadas atividades, aumento de produtividade, eficiência, eficácia, controle de suas tarefas e vantagens financeiras (MACHADO; FREITAS, 2009). O uso de dispositivos portáteis e móveis ligados à internet permite chamada de voz e de vídeo, transmissão de arquivos e implantação de sistemas integrados no próprio aparelho, contribuindo para a comunicação e acesso à informação.

Brans e Basole (2008), afirmam que a necessidade do uso das tecnologias móveis por alguns trabalhadores decorre da característica da atividade que exercem vez que o acesso à informação a qualquer hora e em qualquer lugar é essencial para a execução de suas tarefas. Marques e João (2003) ratificam que quanto mais tempo os executivos passam fora da organização, maior é a sua necessidade de informação através de um dispositivo móvel. Profissionais móveis precisam de informações imediatas quando estão fora da organização, vez que tais profissionais podem ser considerados inerentemente móveis sob o ponto de vista operacional, de localização e interativo (KAKIHARA; SØRENSEN, 2002). 
Ademais, é importante salientar que o uso de tecnologias móveis e sem fio está associado ao trabalho móvel, ou seja, ao trabalho realizado longe do ambiente tradicional e em qualquer lugar (CORSO; CAVEDON; FREITAS, 2011). Dessa forma, o trabalho móvel poderá apresentar-se segundo dois aspectos: (a) relacionado a documentos e tarefas que se movem fisicamente ou digitalmente; e (b) pertinente a trabalhadores móveis (ANDRIESSEN; VARTIAINEN, 2006).

Saccol e Reinhard (2007), dentre outros pesquisadores, afirmam que o uso de tecnologias móveis propiciam maior autonomia e responsabilidade aos seus usuários e também à organização. Para Sørensen (2003), o uso de tecnologias móveis tende a auxiliar o usuário no gerenciamento de conflitos e interesses, bem como facilitar a integração entre as pessoas e ajudar no controle das tarefas do trabalho.

Assim como há benefícios da mobilidade tecnológica, também têm surgido estudos centrados nos paradoxos decorrentes do uso de tecnologias móveis no ambiente corporativo, que apontam aspectos negativos. De acordo com Mick e Fournier (1998) e Javenpaa e Lang (2005), o uso de tecnologias móveis tende a gerar paradoxos, tais como: poder ou escravidão, dependência ou independência, satisfação ou criação de necessidades, competência ou incompetência, planejamento ou improvisação, engajamento ou desengajamento, público ou privado, e ilusão ou desilusão.

O uso de tecnologias móveis pode mudar o comportamento do indivíduo em relação ao seu trabalho e ao relacionamento interpessoal (CAVAZOTTE; BROLLO; MORENO JUNIOR, 2009; GONÇALVES; JOIA, 2011). Kakihara e Sørensen (2001), afirmam que a Tecnologia de Informação e Comunicação alterou a forma de se viver socialmente.

Uma pesquisa realizada por Lunardi, Dolci e Wendland (2012) vem a corroborar com essa mudança no relacionamento interpessoal. A fim de entender quais os fatores que levaram organizações a adotarem a internet móvel, a qual provém da adoção de tecnologias de informação móveis, os autores pesquisaram 96 organizações localizadas no Rio Grande do Sul, no período compreendido entre outubro de 2010 e abril de 2011. Segundo os autores, a adoção da internet móvel é influenciada pela utilidade percebida, pelo ambiente organizacional e pelas pressões de mercado. Acesso a e-mails e sites, para fins de realização de operações financeiras, constituem um dos principais motivos de adoção da internet móvel.

Ladd, Datta, Sarker e Yu (2010) elaboraram um modelo para identificar a inter-relação existente entre os motivos da organização e os dos indivíduos no processo de adoção de tecnologias móveis (Figura 1). 


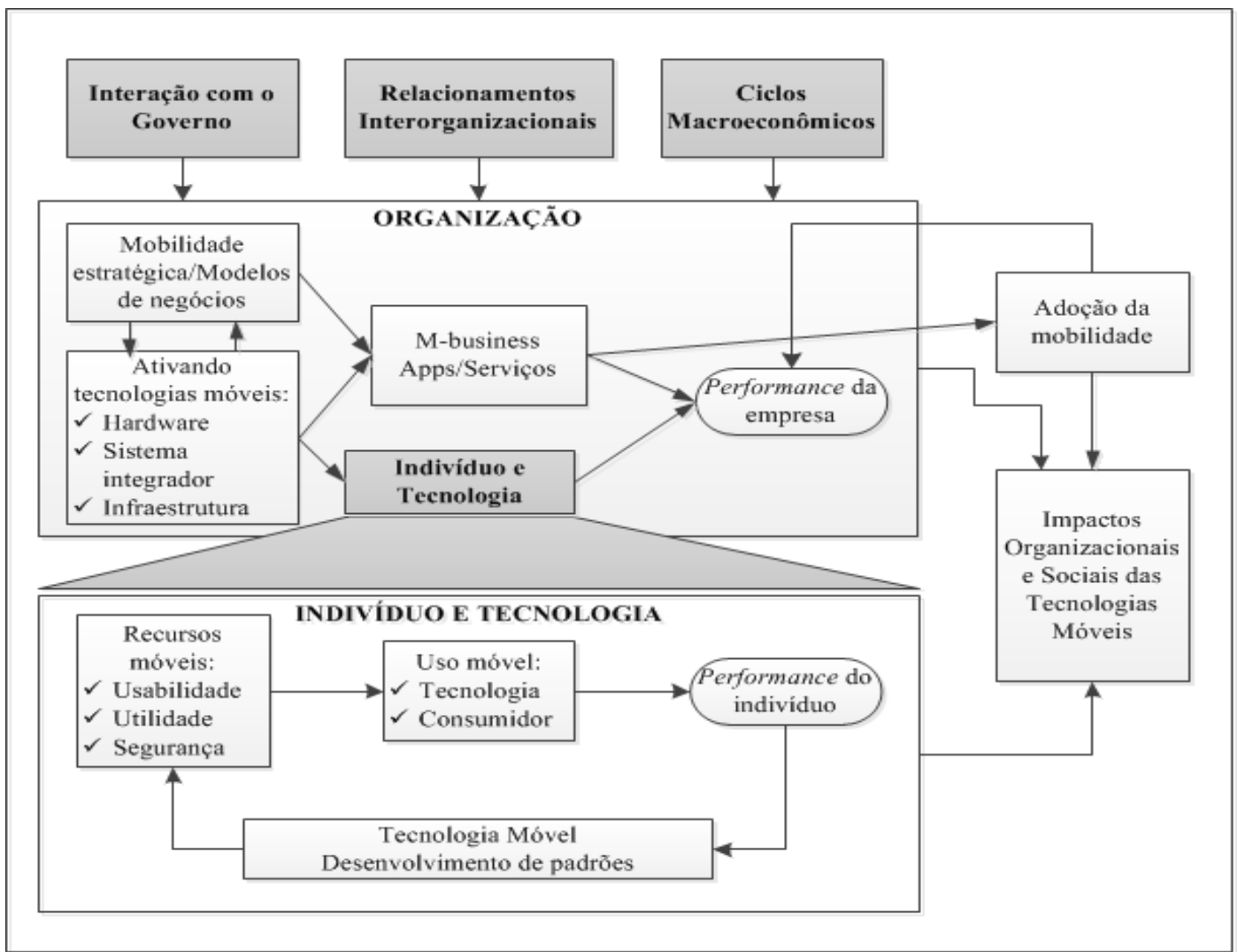

Figura 1. Facetas da computação móvel e suas interrelações (áreas necessitando mais pesquisa são mostradas em cinza)

Fonte: elaborado com base em LADD, D.A.; DATTA, A.; SARKER, S.; YU, Y. Trends in Mobile Computing within the IS Discipline: A Ten-Year Retrospective. In: Communications of AIS (property of Association for Information Systems), v. 27, n. 17, p. 285-306, agosto 2010 .

A adoção e o uso da tecnologia móvel envolvem as estratégias e os modelos de negócios das organizações, bem como a contribuição para a realização das atividades pelo trabalhador e o desempenho deste no ambiente organizacional, assim possibilitando a identificação de contribuições e limitações quanto ao uso de tal tecnologia pelas organizações.

O Quadro 3, elaborado com base nos estudos de Marques e João (2003), Saccol e Reinhard (2005), Manica e Saccol (2009) e Sandi e Saccol (2010), apresenta algumas contribuições e limitações tanto para a organização como para o colaborador propiciadas pelo uso de tecnologias móveis.

Quadro 3. Contribuições e limitações quanto à adoção e ao uso de TIMs

Contribuições Flexibilidade em relação a tempo e espaço; facilidade em se relacionar com clientes; melhoria na integração com unidades distantes geograficamente; melhoria na gestão de negócios com acesso ao sistema de informação móvel; aumento na produtividade com eficiência e eficácia; facilidade no acompanhamento das tarefas da organização em diferentes locais; acesso 


\begin{tabular}{|l|l|}
\hline & $\begin{array}{l}\text { fácil a documentos, dados e atualizações; maior aproveitamento dos } \\
\text { intervalos “tempos mortos"; facilidade na atualização da agenda em tempo } \\
\text { real; facilidade em encontrar pessoas a qualquer lugar e horário; } \\
\text { possibilidade de se trabalhar enquanto se está em movimento; traz a } \\
\text { liberdade aos seus usuários em relação ao trabalho; traz benefícios ao } \\
\text { usuário decorrente do avanço de conhecimentos; ajuda na interação com as } \\
\text { pessoas da própria organização; melhor controle de recursos; acesso direto a } \\
\text { decisões e stakeholders que são fundamentais para a tomada de decisão; } \\
\text { custos baixos para a comunicação; menor utilização de papéis, porque os } \\
\text { usuários não precisam entregar relatórios em papéis; satisfação dos usuários } \\
\text { e da organização. }\end{array}$ \\
\hline Limitações & $\begin{array}{l}\text { O uso pode causar certa desordem; traz a dependência de alguns usuários, } \\
\text { por exemplo, a necessidade de ver a toda hora o e-mail; traz interrupções } \\
\text { desnecessárias, tais como em reuniões; aumento na demanda de respostas } \\
\text { rápidas; perda de privacidade; isolamento, individualismo; sobrecarga de } \\
\text { dados; ineficiência de alguns usuários; má qualidade na conexão; falta de } \\
\text { segurança no próprio dispositivo; capacidade de armazenamento ruim; as } \\
\text { utilidades de sistemas são limitadas; aumento de controle das organizações } \\
\text { sobre as pessoas. }\end{array}$ \\
\hline
\end{tabular}

Fonte: elaborado pelos autores

Besseyre des Horts (2008), por sua vez, aponta que o uso de TIMs pelas organizações propicia tanto benefícios como também riscos às organizações, conforme Quadro 4.

Quadro 4. Benefícios e riscos decorrentes da adoção e do uso de TIMs, segundo Besseyre des Horts (2008)

\begin{tabular}{|l|l|}
\hline Benefícios & $\begin{array}{l}\text { Desenvolvimento da flexibilidade organizacional; ganhos de produtividade; } \\
\text { racionalização dos processos de negócio; receptividade das partes } \\
\text { interessadas, inclusive clientes; desenvolvimento da comunicação e partilha } \\
\text { de conhecimentos; redução das despesas gerais e operacionais; e melhoria na } \\
\text { imagem corporativa. }\end{array}$ \\
\hline Riscos & $\begin{array}{l}\text { Risco cultural; segurança dos sistemas de informação; perda de comunicação; } \\
\text { declínio na qualidade da tomada de decisão; medição de retorno sobre o } \\
\text { investimento; e decomposição gradual do trabalho coletivo. }\end{array}$ \\
\hline
\end{tabular}

Fonte: elaborado pelos autores.

Por fim, considera-se que a mobilidade tem potencial de promover profundas transformações nos processos de trabalho, nos modelos de negócios e na relação entre equipes de trabalho, o que pode vir a contribuir para a inovação e o empreendedorismo no contexto organizacional. Essa relação entre empreendedorismo e mobilidade será explorada com mais profundidade na próxima seção, com base na literatura visitada.

\section{ORIENTAÇÃO EMPREENDEDORA (OE) E MOBILIDADE: UMA APROXIMAÇÃO CONCEITUAL}


A revisão conceitual apresentada possibilita fazer uma primeira aproximação entre as dimensões da OE e a alguns aspectos da mobilidade decorrente do uso de tecnologias móveis no âmbito organizacional.

De um modo geral, a literatura sugere que fatores individuais, organizacionais e ambientais influenciam o empreendedorismo e a OE (LUMPKIN; DESS, 1996; SHANE; VENKATARAMAN, 2000). Ademais, uma organização com forte OE apresenta como características primordiais a propensão a assumir riscos e a atuar de forma autônoma, uma atitude proativa perante as oportunidades de mercado que se vislumbrarem, a busca constante por inovações e uma postura agressiva perante seus concorrentes, reagindo de modo imediato às ações desses últimos (LUMPKIN; DESS, 1996).

Analisando as questões relacionadas à autonomia, com base na literatura pesquisada, depreende-se que essa dimensão da $\mathrm{OE}$ está intimamente relacionada ao comportamento dos indivíduos que atuam nas organizações, bem como que o fato desta incentivar a postura autônoma de seus colaboradores lhe permite ter uma atitude orientada ao empreendedorismo (MARTENS; FREITAS; ANDRES, 2011). O uso de dispositivos móveis viabiliza a realização de atividades fora do local de trabalho, a flexibilidade em relação a tempo e espaço (MARQUES; JOÃO, 2003; SANDI; SACCOL, 2010), a possibilidade de se trabalhar enquanto se está em movimento (SANDI; SACCOL, 2010), a melhoria na integração com unidades distantes geograficamente ( MANICA, SACCOL, 2009; SANDI; SACCOL, 2010), o que pode contribuir para a autonomia de indivíduos e de equipes. Adicionalmente, os indivíduos podem decidir em que local e em que momento desenvolver as atividades, bem como quando utilizar tais dispositivos.

A inovatividade é outra dimensão da $\mathrm{OE}$ que encontra guarida no processo de adoção e uso de tecnologias móveis. No momento em que uma organização decide por fazer uso dessas novas tecnologias, mudanças em seus processos administrativos e tecnológicos são instauradas, tais como: aquisição e implantação de novas plataformas tecnológicas, treinamento dos recursos humanos a fim de operarem a nova tecnologia, alteração em processos de trabalho, aquisição de dispositivos móveis adequados aos objetivos que a organização deseja atingir, entre outras.

Adicionalmente, o uso de tecnologias móveis pode propiciar às organizações novas formas de relacionamento com seus stakeholders, podendo contribuir para a inovação em processos, na prestação de serviços e no oferecimento de produtos (novos ou não). 
Desenvolvimento da flexibilidade organizacional (MARQUES; JOÃO, 2003; BESSYRE DES HORTS, 2008; SANDI; SACCOL, 2010), ganhos de produtividade (MARQUES; JOÃO, 2003; BASOLE, 2008; BESSYRE DES HORTS, 2008; MANICA; SACCOL, 2009; SANDI; SACCOL, 2010) e racionalização dos processos de negócio (BESSYRE DES HORTS, 2008; SANDI; SACCOL, 2010) são alguns exemplos que podem decorrer da adoção de TIMs e contribuir para a inovatividade. Tal fato corrobora com os elementos característicos da OE, identificados por Martens, Freitas e Andres (2011) em organizações que atuam com tecnologia da informação.

Atrelada à inovatividade está a dimensão assunção de riscos. A predisposição de uma organização a assumir riscos, sejam eles decorrentes da própria operação da organização, sejam relacionados a decisão, financeiros ou em negócios, também está atrelada ao comportamento dos indivíduos. Da mesma forma, a tendência da organização em assumir projetos arriscados e ações ousadas por parte de seus gestores a fim de atingir os objetivos corporativos dizem respeito à assunção de riscos (LUMPKIN; DESS, 1996; MARTENS; FREITAS; BOISSIN, 2011). Riscos estão relacionados a situações que podem gerar incertezas, ou seja, ao optar por assumir riscos os decisores assumem a probabilidade de obter ou não êxito acerca de sua decisão. O uso de TIMs propicia acesso direto a informações e stakeholders que são fundamentais para a tomada de decisão (MANICA; SACCOL, 2009; SANDI; SACCOL, 2010), ajuda na interação com as pessoas da própria organização (MARQUES; JOÃO, 2003; MANICA; SACCOL, 2009), aspectos que podem contribuir para a assunção de riscos calculados.

As tecnologias móveis podem propiciar muitas contribuições e benefícios às organizações que as adotarem, porém também levam a condições de riscos e incertezas, vez que dispositivos móveis não são baratos, exigem aplicativos próprios dependendo de sua finalidade, são passíveis de furto, roubo ou até mesmo de invasão de privacidade. Nesse sentido, a adoção do uso de tecnologias móveis por parte de uma organização, por si só, configura assunção de riscos. Aliado a isso, a própria ampliação do acesso à informação, por exemplo, pode contribuir para a agilidade na tomada de decisão e o acesso a mais subsídios para embasar a decisão, potencialmente contribuindo para a avaliação de riscos na decisão.

A dimensão proatividade pode ser retratada por busca por novas oportunidades, antecipação a mudanças, planejamento e participação em resolução de problemas, flexibilidade tecnológica e monitoramento do ambiente (LUMPKIN; DESS, 1996; MARTENS; FREITAS; BOISSIN, 2010; MARTENS; FREITAS; ANDRES, 2011). 
Conforme já mencionado, as tecnologias móveis permitem à organização e aos indivíduos mobilidade e flexibilidade de uso, tempo e local. Ao mesmo tempo, as tecnologias móveis permitem à organização realizar um acompanhamento contínuo tanto do seu ambiente externo como de seu ambiente interno, propiciando-lhe melhor controle de recursos (MANICA; SACCOL, 2009), facilita a identificação de novas oportunidades de atuação antes de seus concorrentes.

A quinta e última dimensão da $\mathrm{OE}$, agressividade competitiva, diz respeito às ações das organizações para superarem seus concorrentes (LUMPKIN; DESS, 1996; FREITAS; MARTENS; BOISSIN; BEHR, 2012), porém de um modo reativo, diferentemente da dimensão proatividade. Com vistas a atuar de modo competitivo, com ações agressivas de marketing e respostas rápidas aos movimentos da concorrência, as organizações que se utilizam de tecnologias móveis podem beneficiar-se delas para atuar de forma mais competitiva, o que pode ser facilitado pelo acesso fácil a documentos, dados e atualizações (SANDI; SACCOL, 2010), por exemplo.

Uma análise mais detalhada da literatura sobre as dimensões da OE possibilita elencar elementos característicos da autonomia, da inovatividade, da assunção de riscos, da proatividade e da agressividade competitiva, que podem ser utilizados como base para estudar os efeitos do uso de tecnologias móveis sobre o empreendedorismo organizacional. O Quadro 5 apresenta tais elementos, que podem ser considerados como base para realização de estudo empírico a esse respeito. Para sua elaboração, foram utilizados como base os estudos de Covin e Slevin (1989), Lumpkin (1998 apud LUMPKIN; DESS, 2001), Lumpkin e Dess (2001), Lumpkin, Cogliser e Schneider (2009), e Freitas, Martens, Boissin e Behr (2012).

Quadro 5. Elementos da orientação empreendedora a considerar em estudo sobre os efeitos da mobilidade sobre o empreendedorismo organizacional

Inovatividade - $\mathrm{O}$ uso de tecnologias móveis nas atividades profissionais diárias...

...favorece iniciativas relacionadas à pesquisa e desenvolvimento e inovação.

...possibilita à organização inovar em produtos e/ou serviços.

...possibilita à organização inovar em processos internos (administrativos, produção, mercado, etc).

...contribui para a organização aumentar a participação no mercado.

Assunção de riscos - $O$ uso de tecnologias móveis nas atividades profissionais diárias... ...contribui para uma atitude audaciosa perante o mercado.

...contribui para a avaliação e mensuração de riscos.

...contribui para a agilidade na tomada de decisões, sobretudo em situações de incerteza.

Proatividade - $\mathrm{O}$ uso de tecnologias móveis nas atividades profissionais diárias...

...contribui para que a organização inicie no mercado ações às quais os competidores respondem.

...contribui para que a organização seja a primeira a introduzir novos produtos/serviços no 
mercado, novas técnicas administrativas, novas tecnologias operacionais, etc.

...contribui para o monitoramento do ambiente (clientes, concorrentes, busca de oportunidades, etc).

...contribui para que a organização se antecipe na identificação de oportunidades do mercado.

Autonomia - O uso de tecnologias móveis nas atividades profissionais diárias...

...contribui para a resolução de problemas.

...contribui para que indivíduos e/ou equipes trabalhem de forma autônoma.

...contribui para que indivíduos e/ou equipes tomem decisões por conta própria.

...contribui para que os colaboradores exerçam um papel importante na identificação e seleção de oportunidades.

...favorece o desenvolvimento do comportamento empreendedor dos colaboradores.

Agressividade competitiva - $\mathbf{O}$ uso de tecnologias móveis nas atividades profissionais diárias...

...permite à organização reagir agressivamente às ações da concorrência.

...permite à organização utilizar métodos de competição não convencionais.

...permite à organização realizar benchmarking competitivo.

...possibilita à organização promover ações agressivas em marketing.

Fonte: elaborado pelos autores.

De um modo geral, a análise da literatura sobre orientação e mobilidade de forma conjunta sugere a existência de relação entre a adoção e uso de tecnologias móveis e as dimensões da OE. O Quadro 6 apresenta algumas reflexões a esse respeito.

Quadro 6. Reflexões iniciais sobre a relação entre a as dimensões da orientação empreendedora e a mobilidade.

\begin{tabular}{|l|l|}
\hline Dimensões da OE & Considerações a respeito do uso de tecnologias móveis \\
\hline $\begin{array}{l}\text { Autonomia: } \\
\text { A organização preza a ação } \\
\text { independente de equipes } \\
\text { autônomas e de colaboradores. }\end{array}$ & $\begin{array}{l}\text { O uso de tecnologias móveis permite que profissionais } \\
\text { desenvolvam suas atividades sem a necessidade de estar } \\
\text { no escritório físico da organização, e a qualquer horário, o } \\
\text { que pode vir a contribuir com o desenvolvimento da } \\
\text { autonomia. Inclui o acesso a informações remotas e a } \\
\text { possibilidade de trabalho remoto de colaboradores e } \\
\text { equipes. }\end{array}$ \\
\hline $\begin{array}{l}\text { Dimensões da OE } \\
\text { A organização se engaja e } \\
\text { apoia novas ideias, novidades, } \\
\text { experimentos e processos } \\
\text { criativos que possam resultar } \\
\text { em novos produtos, serviços ou } \\
\text { processos. }\end{array}$ & $\begin{array}{l}\text { Âmedida que as tecnologias móveis afetam o modo de } \\
\text { trabalhar e por vezes os processos de negócios, imagina- } \\
\text { se que essas alterações possam propiciar elementos de } \\
\text { inovatividade no contexto organizacional. Por exemplo, o } \\
\text { processo de trabalho pode sofrer inovações incrementais, } \\
\text { bem como a prestação de serviços e o atendimento ao } \\
\text { cliente, a racionalização dos processos de negócio, entre } \\
\text { outros. }\end{array}$ \\
\hline $\begin{array}{l}\text { Assunção de riscos: } \\
\text { A organização possui } \\
\text { propensão a assumir riscos e a } \\
\text { se engajar em projetos de alto }\end{array}$ & $\begin{array}{l}\text { Como toda mudança, a adoção de uma nova TI também } \\
\text { pode trazer riscos para a organização. A resistência à } \\
\text { mudança pode ser um elemento a considerar, assim como } \\
\text { a segurança da informação, o risco financeiro embutido }\end{array}$ \\
\hline
\end{tabular}




\begin{tabular}{|l|l|}
\hline risco. & $\begin{array}{l}\text { no investimento de TIMs eventualmente motivado por } \\
\text { exigências do mercado ou por reação à concorrência, sem } \\
\text { se assegurar do retorno. } \\
\text { Outros aspectos a considerar são o acesso direto a } \\
\text { decisões e stakeholders que são fundamentais para a } \\
\text { tomada de decisão, bem como o desenvolvimento da } \\
\text { comunicação e partilha de conhecimentos. }\end{array}$ \\
\hline $\begin{array}{l}\text { Proatividade: } \\
\text { A organização antecipa-se ao } \\
\text { mercado e aproveita } \\
\text { oportunidades, influenciando o } \\
\text { ambiente ou iniciando } \\
\text { mudanças. }\end{array}$ & $\begin{array}{l}\text { O acesso remoto às informações e pessoas pode } \\
\text { contribuir para a proatividade, na busca de antecipar-se às } \\
\text { oportunidades do mercado e ações da concorrência. A } \\
\text { mobilidade das pessoas e equipes são alguns elementos } \\
\text { que podem contribuir para o comportamento proativo, } \\
\text { bem como a agilidade propiciada pelo uso de tecnologias } \\
\text { móveis. }\end{array}$ \\
\hline $\begin{array}{l}\text { Agressividade competitiva: } \\
\text { A organização reage à } \\
\text { concorrência e às ameaças do } \\
\text { mercado, com respostas } \\
\text { rápidas a ações do mercado } \\
\text { concorrente. }\end{array}$ & $\begin{array}{l}\text { A rápida reação ao mercado concorrente pode vir a ser } \\
\text { facilitada por meio do acesso remoto a informações, } \\
\text { aliada à agilidade para decisão e reação que as } \\
\text { tecnologias móveis propiciam, trazendo contribuições } \\
\text { para a agressividade competitiva. }\end{array}$ \\
\hline
\end{tabular}

Fonte: elaborado pelos autores.

O Quadro 6 representa um primeiro esforço no sentido de aproximar os eixos teóricos centrais deste estudo (orientação empreendedora e mobilidade empresarial) no sentido de identificar pontos comuns entre ambos, que podem potencialmente ser refletidos na prática organizacional. Acrescenta-se a esse aspecto o fato de que a utilização de dispositivos móveis pelas organizações na realização de suas atividades tende a contribuir para uma postura orientada ao empreendedorismo, uma vez que podem propiciar a incorporação da $\mathrm{OE}$ à estratégia organizacional; e consequentemente, uma maior proximidade de novas tecnologias, de seus mercados e stakeholders (ALOULOU; FAYOLLE, 2005).

\section{CONSIDERAÇÕES FINAIS}

O presente artigo propôs identificar relações conceituais entre a orientação empreendedora e a mobilidade decorrente do uso de tecnologias móveis. Para atingir o objetivo proposto, a literatura pertinente aos dois eixos teóricos foi revisitada e analisada de forma conjunta. Uma das possíveis evidências que permitem considerar essa relação entre os dois eixos diz respeito ao fato de que tanto a OE (COVIN; GREEN; SLEVIN, 2006) como a adoção de TIMs (LADD, DATTA; SARKER; YU, 2010) podem contribuir para o alcance dos objetivos organizacionais. Da mesma forma, pode-se afirmar que uma organização que 
adota o uso de dispositivos móveis em suas atividades está inovando em produtos, processos e tecnologias, agindo com ousadia e autonomia, seja antecipando-se às ações de seus concorrentes ou reagindo agressivamente a tais ações.

Nesse sentido, considerando a questão de pesquisa que delineou o presente estudo - a orientação empreendedora de uma organização pode ser afetada pelo uso de tecnologias móveis? - como resultado, apresenta-se um quadro comparativo com reflexões prévias sobre a relação entre as dimensões da orientação empreendedora e a mobilidade (Quadro 6). Essas reflexões, ainda que preliminares e baseadas na literatura visitada, permitem sugerir que a mobilidade pode ter efeitos positivos nas dimensões da OE de uma organização.

Embora a análise da literatura permita sugerir que a mobilidade afete o empreendedorismo organizacional, são necessários estudos empíricos para sua verificação na prática organizacional. Recomenda-se estudo de abordagem exploratória e qualitativa, para melhor compreensão do fenômeno, seguido de estudo quantitativo, que possa levar à identificação da relação entre mobilidade e OE. O Quadro 5 apresenta elementos das dimensões da OE que podem embasar estudos com esse propósito.

Face essa aproximação conceitual, novos questionamentos surgem a partir da análise apresentada no presente artigo, assim motivando novos estudos: As reflexões preliminares sobre os efeitos da mobilidade sobre o empreendedorismo organizacional apresentadas neste artigo são verificadas na prática organizacional? Quais os efeitos da mobilidade sobre a inovatividade, a assunção de riscos, a proatividade, a autonomia e a agressividade competitiva? A mobilidade pode ser considerada um elemento potencializador do empreendedorismo organizacional? Esses e outros questionamentos podem ser a base para o desenvolvimento de estudos empíricos que relacionem o empreendedorismo e a mobilidade em contexto organizacional.

Este estudo apresenta contribuições para a academia e para a prática organizacional. No contexto acadêmico, trata-se de um primeiro passo nos estudos e discussões acerca da relação entre mobilidade empresarial e OE, dada a lacuna de estudos a esse respeito. Em termos de prática organizacional, o estudo remete à reflexão sobre o papel das tecnologias móveis, presentes nas organizações de forma crescente, como fator potencialmente alavancador da inovação e do empreendedorismo no âmbito organizacional. Os Quadros 5 e 6 contribuem para reflexões nesse contexto, por pesquisadores ou por executivos.

As limitações que norteiam esse artigo estão relacionadas à necessidade de estudos empíricos a respeito das relações conceituais analisadas. As reflexões apresentadas no Quadro 
6 foram baseadas na literatura visitada, e são merecedoras de novos estudos que permitam realizar e aprofundar os resultados aqui apresentados. 


\section{REFERÊNCIAS}

ALOULOU, W.; FAYOLLE, A. A conceptual approach of entrepreneurial orientation within small business context. Journal of Enterprising Culture, v. 13, n. 1, p. 21-45, March 2005.

ALBERTIN, A. L. Valor estratégico dos projetos de tecnologia de informação. RAE, São Paulo, v. 41, n. 3, p. 42-50, jul./set. 2001.

ALBERTIN, A. L.; ALBERTIN, R. M. M. Tecnologia de informação e desempenho empresarial no gerenciamento de seus projetos: um estudo de caso de uma indústria. RAC, Curitiba, v. 12, n. 3, p. 599-629, jul./set. 2008.

ANDRIESSEN, E.; VARTIAINEN, M. Emerging Mobile Virtual Work. In E. Andriessen \& M. Vartiainen (Eds.) Mobile Virtual Work: A New Paradigm? Heidelberg: Springer, 2006.

BASOLE, R. C. Enterprise mobility: researching a new paradigm. Information Knowledge Systems Management, v. 7, n. 1, p. 1-7, 2008.

BELFORT, A. C.; MARTENS, C. D. P. Equipes virtuais de projetos, mobilidade do trabalho e uso de tecnologias de informação móveis: um estudo teórico empírico. Revista ADM.MADE, v. 18, n. 1, p. 32-55, 2014.

BESSEYRE DES HORST, C. H.; ISAAC, H.; LECLERCQ, A. (2006, 16 et 17 novembre). Les consequences paradoxales de l'usage des outils mobiles de communication sur les situations perçues de travail: une etude exploratoire sur l'impact humain et organi-sationnel des technologies mobiles. In: XVIIe Congrès de l'AGRH - Le travail au coeur de la GRH, 16 et 17 novembre 2006, Reims. Anais... Reims, IAE de Lille et Reims Management School, 2006, p. 1-20.

BESSEYRE DES HORST, C. H. L'entreprise mobile: comprendre l'impact des nouvelles technologies. Paris: Pearson Education France, 2008.

BRANS, P. D.; BASOLE, R. C. A comparative anatomy of mobile enterprise applications: towards a framework of software reuse. Information Knowledge Systems Management, n. 7, p. 145-158, 2008.

BROADBENT, M.; WEILL, P. Management by maxim: how business and IT managers can create IT infrastructures. Sloan Management Review, p. 77-92, Spring 1997.

CASTANHAR, J. C.; DIAS, J. F.; ESPERANÇA, J. P. Orientação Empreendedora, Reconhecimento de Oportunidades e Desempenho em Pequenas e Médias Empresas Brasileiras: Evidências de 2 Estudos de Caso. In: XXX Encontro da AnPAD, Salvador, BA. Anais... Salvador, 2006.

CAVAZOTTE, F. S.; BROLlO, M. S.; MORENO JUNIOR, V. A. Mobilidade computacional no trabalho: um estudo sobre a experiência de usuários de telefones inteligentes. In: XXXIII Encontro da AnPAD, São Paulo, SP. Anais... São Paulo, 2009.

CHUNG, S.; LEE, K. Y.; CHOI, J. Exploring digital creativity in the workspace: The role of enterprise mobile applications on perceived job performance and creativity. Computers in Human Behavior, 2014 (Article in press).

CORNELIUS, B.; LANDSTRÖM, H.; PERSSON, O. Entrepreneurial studies: the dynamic research front of a developing social science. Entrepreneurial: Theory and Research, v. 30, n. 3, p. 375-398, May 2006.

CORSO, K. B.; CAVEDON, N. R.; FREITAS, H. Mobilidade Espacial, Temporal e Contextual: um estudo de inspiração etnográfica sobre o Trabalho Móvel em Shopping Center. In: ENaDI 2011 - III Encontro de Administração da Informação, Porto Alegre/RS. Anais... Porto Alegre, 2011.

COVIN, J. G.; GREEN, K. M.; SLEVIN, D. P. Strategic process effects on the entrepreneurial orientation-sales growth rate relationship. Entrepreneurship: Theory \& Practice, v. 30, n. 1, p. 57-82, 2006. 
COVIN, J. G.; LUMPKIN, G. T. Entrepreneurial Orientation Theory and Research: Reflections on a Needed Construct. Entrepreneurship: Theory \& Practice, v. 35, n. 5, p. 855-872, Sep. 2011.

COVIN, J. G.; SLEVIN, D. P. Strategic management of small firms in hostile and benign environments. Strategic Management Journal, v. 10, n. 1, p. 75-87, 1989.

COVIN, J. G.; SLEVIN, D. P. A conceptual model of entrepreneurship as firm behavior. Entrepreneurship: Theory \& Practice, v. 16, n. 1, p. 7-25, 1991.

ENGELEN, A.; KUBE, H.; SCHMIDT, S.; FLATTEN, T. C. Entrepreneurial orientation in turbulent environments: the moderating role of absorptive capacity. Research Policy, v. 17, Article in press.

FERNANDES, D. V. D. H.; SANTOS, C. P. Orientação Empreendedora: um estudo sobre as consequências do empreendedorismo nas organizações. RAE-eletrônica, v. 7, n. 1, Art. 6, jan./jun. 2008.

FREITAS, H.; MARTENS, C. D. P.; BOISSIN, J. P.; BEHR, A. Elementos para guiar ações visando à orientação empreendedora em organizações de software. Revista de Administração - RAUSP, São Paulo, v. 47, n. 2, p. 163-179, abr./mai./jun. 2012.

GIL, A. C. Como elaborar projetos de pesquisa. 5 ed. São Paulo: Atlas, 2010.

GONÇALVES, A.; JOIA, L. Uma investigação acerca dos paradoxos presentes na relação entre executivos e smartphones. In: XXXV Encontro da EnANPAD, Rio de Janeiro, 4 a 7 de Setembro, CD ROM. Anais... Rio de Janeiro, 2011.

GRÉGOIRE, D. A.; NOËL, M. X.; DÉRY, R.; BÉCHARD, J-P. Is there conceptual convergence in entrepreneurship research? A co-citation analysis of frontiers of entrepreneurship research 1981-2004. Entrepreneurship: Theory \& Practice, v.30, n.3, p. 337-373, 2006.

HENDERSON, J. C.; VENKATRAMAN, N. Strategic alignment: leveraging Information technology for transforming organizations. IBM Systems Journal, v. 32, n. 1, p. 4-16, 1993. IDC LATIN. Top 10 Predictions - IDC Latin America Predictions 2014. Disponível em: http://www.idclatin.com/campaign/predictions/. Acesso em 31/07/2014.

IDC BRASIL. IDC Brasil: em 2014, US\$ 175 bilhões serão investidos em TIC no País, que se consolida como $4^{\circ}$ maior mercado do mundo. IDC Releases. São Paulo, 05 fev. 2014. Disponível em: http://www.idcbrasil.com.br/releases/news.aspx?id=1588. Acesso em 31/07/2014.

IDC BRASIL. Estudo da IDC aponta que mercado brasileiro de celulares encerrou 2013 com a marca recorde de 67,8 milhões de unidades comercializada. IDC Releases. São Paulo, 02 abr. 2014. Disponível em: http://br.idclatin.com/releases/news.aspx?id=1613. Acesso em 31/07/2014.

IDC BRASIL. Tablets superam notebooks em vendas pela primeira vez, segundo estudo da IDC. IDC Releases. São Paulo, 03 abr. 2014. Disponível em: http://br.idclatin.com/releases/news.aspx?id=1627. Acesso em 31/07/2014.

JARVENPAA, S. L.; LANG, K. R. Managing the paradoxes of mobile technology. Information Systems Management, v. 22, n. 4, p. 7-23, Fall 2005.

KAKIHARA, M.; SORENSEN, C. Expanding the 'Mobility' Concept. ACM SIGGROUP Bulletin, v. 22, n. 3, p. 33-37, 2001.

KALAKOTA, R.; ROBINSON, M. M-business: tecnologia móvel e estratégia de negócios. Porto Alegre: Bookman, 2002.

KLEINROCK, L. Nomadicity: Anytime, anywhere in a disconnected world. Mobile Networks and Applications, Science Publishers, v. 1, n. 4, p. 351-357, 1996.

LADD, D. A.; DATTA, A.; SARKER, S.; YU, Y. Trends in Mobile Computing within the IS Discipline: A Ten-Year Retrospective. Communications of Association for Information Systems, v. 27, n. 1, p. 285-306, august 2010. 
LAKATOS, E. M.; MARCONI, M. A. Fundamentos da metodologia científica. 7 ed. São Paulo: Atlas, 2010.

LANDSTRÖN, H.; HARIRCHI, G.; ASTRÖN, F. Entrepreneurship: exploring the knowledge base. Research Policy, v. 41, p. 1154-1181, 2012.

LAURINDO, F. J. B.; SHIMIZU, T.; CARVALHO, M. M.; RABECHINI Jr., R. O papel da tecnologia da informação (TI) na estratégia das organizações. Gestão \& Produção, v. 8, n. 2, p. 160-179, agosto 2001.

LUMPKIN, G. T.; DESS, G. G. Clarifying the entrepreneurial orientation construct and linking it to performance. Academic of Management Review, v. 21, n. 1, p. 135-172, 1996.

LUNARDI, G. L.; DOLCI, D. B.; WENDLAND, J. Adoção da Internet Móvel e seu Impacto no Desempenho Organizacional. In: XXXVI Encontro da AnPAD. Rio de Janeiro. Anais... Rio de Janeiro, 2012.

MACHADO, C. B.; FREITAS, H. Planejamento de iniciativas de adoção de tecnologias móveis. Gestão de Produção, Operações e Sistemas, v. 1, n. 1, p. 101-115, jan./mar. 2009.

MANICA, A.; SACCOL, A. I. C. Z. Avaliação dos resultados de adoção de tecnologias da informação móveis e sem fio (TIMS): O caso IBGE - CENSO 2007. In: XXXIII Encontro da AnPAD. São Paulo. Anais... São Paulo, 2009.

MARQUES, E.; JOÃO, B. N. Mobilidade: uma investigação de uso por executivos brasileiros. In: XXVII Encontro Nacional dos Programas de Pós-Graduação em Administração, Atibaia, SP, Brasil. Anais... Atibaia, 2003.

MARTENS, C. D. P.; FREITAS, H.; ANDRES, R. Desenvolvimento da orientação empreendedora em empresas de software: proposições preliminares. REAd, v. 69, n. 2, p. 424-450, mai/ago 2011.

MARTENS, C. D. P.; FREITAS, H. M.; BOISSIN, J.-P. Proatividade em empresas de software empreendedoras: a voz dos executivos. Gestão.Org, v. 8, n. 3, p. 327-354, set./dez. 2010.

MARTENS, C. D. P.; FREITAS, H. M.; BOISSIN, J.-P.. Risk-taking in software companies: a sector study in Rio Grande do Sul. RAUSP. Revista de Administração, v. 46, n. 3, p. 213 227, jul./ago./set. 2011.

MARTINS, G. A.; THEÓPHILO, C. R. Metodologia da investigação cientifica para ciências sociais aplicadas. 2 ed. São Paulo: Atlas, 2009.

MELLO, S. C. B.; PAIVA JUNIOR, F. G.; SOUZA NETO, A. F.; LUBI, L. H.O. Orientação Empreendedora e Competências de Marketing no Desempenho Organizacional: um estudo em Empresas de Base Tecnológica. Organizações \& Sociedade, v. 13, n. 36, p. 185-202, 2006. MENDIETA, A. C.; MARTENS, C. D. P.; BENTO, F. O.; LACERDA, F. M. O uso de tecnologias móveis e a orientação empreendedora: estudo em uma organização de capitalização. Revista Eletrônica de Estratégia e Negócios, v. 6, n. 3, p. 212-237, 2013.

MICK, D. G.; FOURNIER, S. Paradoxes of technology: consumer cognizance, emotions, and coping strategies. Journal of Consumer Research Inc., v. 25, n. 2, p. 123-143, Sep. 1998. MILLER, D. The correlates of entrepreneurship in three types of firms. Management Science, v. 29, n. 7, p. 770-791, july 1983.

RAUCH, A.; WIKLUND, J.; LUMPKIN, G. T.; FRESE, M. Entrepreneurial orientation and business performance: An assessment of past research and suggestions for the future. Entrepreneurship: Theory \& Practice, v. 33, n. 3, p. 761-781, may 2009.

SACCOL, A. I. C. Z.; REINHARD, N. Processo de adoção e decorrências da utilização de tecnologias de informação móveis e sem fio no contexto organizacional. In: XXIX EnANPAD - Encontro da ANPAD, Brasília/DF. Anais... Brasília, 2005.

SACCOL, A.; REINHARD, N. Tecnologias de informação móveis, sem fio e ubíquas: definiçőes, estado-da-arte e oportunidades de pesquisa. RAC, v. 11, n. 4, p. 175-198, 2007. 
SANDI, L. B.; SACCOL, A. Z. Sobrecarga de informações geradas pela adoção de tecnologias da informação móveis e sem fio e suas decorrências para profissionais de vendas. Revista Eletrônica de Sistemas de Informação, v. 9, n. 2, outubro 2010.

SCHILDT, H. A.; ZAHRA, S. A.; SILLANPÄÄ, A. Scholarly communities in entrepreneurship research: a co-citation analysis. Entrepreneurship: Theory \& Practice, v. 30, n. 3, p. 399-415, 2006.

SCORNAVACCA, E.; BARNES, S. J. The strategic value of enterprise mobility: Case study insights. Information Knowledge Systems Management, v. 7, n. 1, p. 227-241, 2008.

SHANE, S.; VENKATARAMAN, S. The promise of entrepreneurship as a field of research. The Academy of Management Review, v. 25, n. 1, p. 217-226, January 2000.

SHEKHAR, S. Understanding the virtuality of virtual organizations. Leadership \& Organization Development Journal, v. 27, n. 6, p. 465-483, 2006.

SHORT, J. C.; KETCHEN, Jr., D. J.; COMBS, J. G.; IRELAND, R.D. Research Methods in Entrepreneurship. Organizational Research Methods, v. 13, n. 1, p. 6-15, Jan. 2010.

SILVA, M. A. O. M.; GOMES, L. F. A. M.; CORREIA, M. F. Cultura e Orientação Empreendedora: uma Pesquisa Comparativa entre Empreendedores em Incubadoras no Brasil e em Portugal. Revista de Administração Contemporânea, Curitiba, v. 13, n. 1, p. 57-71, jan/mar 2009.

SØRENSEN, C. Research issues in mobile informatics: classical concerns, pragmatic issues and emerging discourses. In: Workshop on Ubiquitous Working Environment at Whitehead School of Management, Cleveland, Ohio, USA. Anais... Ohio, 2003.

UNHELKAR, B.; MURUGESAN, S. The enterprise mobile applications development framework. IT Professional, v. 12, n. 3, p. 33-39, 2010.

WALES, W.; MONSEN, E.; MCKELVIE, A. The organizational perva-siveness of entrepreneurial orientation. Entrepreneurship: Theory \& Practice, v. 35, n. 5, p. 895-923, september 2011.

WIKLUND, J. The sustainability of the entrepreneurial orientation-performance relationship. Entrepreneurship: Theory \& Practice, v. 24, n. 1, p. 37-48, 1999.

WIKLUND, J.; SHEPHERD, D. A. Entrepreneurial orientation and small business performance:a configurational approach. Journal of Business Venturing, v.20, n.1, p. 71-91, 2005.

ZAHRA, S. A. A conceptual model of entrepreneurship as firm behaviour: a critique and extension. Entrepreneurship: Theory \& Practice, v. 17, n. 4, p. 5-21, 1993.

ZAHRA, S. A.; COVIN, J. G. Contextual influences on the corporate entrepreneurship performance relationship: a longitudinal analysis. Journal of Business Venturing, v. 10, n. 1, p. 43-58, Jan. 1995.

ZEHIR, C.; MUCELDILI, B.; AKYUZ, B.; CELEP, A. The impact of information technology investments on firm performance in national and multinational companies. Journal of Global Strategic Management, v. 7, p. 143-154, junho 2010. 